\title{
Lack of Family Planning: The Highlighted Burden
}

Munira Minaz Ali \& Alizah Alaman

Agha khan university Hospital, Nursing Department.

Abstract

Family planning is defined as a practice through which number of children and the intervals between their births can be controlled. The need of using contraceptives cannot be neglected in Pakistan, as this would result in unwanted pregnancies and un-safe abortions. Illiteracy, lack of knowledge, fear of side effects, and other socio-cultural factors create obstacles in using family planning methods. These obstacles in turn create adverse impacts on women health and society. For instance, failure to use contraceptives can cause unintended pregnancies which would leave the women at the risk of pregnancy related complications resulting in maternal morbidity and mortality. Moreover, multiple pregnancies also cause financial and social distress resulting in lack of ability to fulfill basic needs of a child. Thus, important measures need to be taken to alleviate the precipitating factors and to improve maternal and child health.

\section{Keywords}

Family planning, sexual health, unwanted pregnancies

\section{Introduction}

"Sexual health is a state of physical, social and mental well-being in relation to sexuality" (WHO, 2014). However, to attain the flavor of this combination, proper family planning is required. Although various family planning methods are available, Pakistan remains high in maternal mortality rate resulting from unwanted pregnancies and unsafe abortions. National Institute of Population Studies Islamabad (2013) defines family planning as method that allows the couple to decide for desired number of children with the appropriate time interval between each birth. It is attained through the use of contraceptives.

Reflecting the socio-cultural significance, Robinson (2012) highlighted that the contraceptive prevalence rate in Pakistan is $30 \%$. But unmet need still stands for $25 \%$. Jackson (2013) stated that using contraceptives can improve reproductive health, lessens the stress of population growth and its negative impacts on country. Moreover, it improves women autonomy by reinforcing right to reproductive choice and attainment of other rights like education, health and life with dignity. However, prevalence shows that more than half of the population isn't using family planning method and end up in unwanted pregnancies and unsafe abortions. I encountered a 21year-old female married to a farmer whose age was 29. She had 2 children, first child was 3 years old and other child was 1.5-yearold. When she was pregnant for the third time, she aborted the baby due to financial problems. Now she was again pregnant and anemic. She went to doctor for abortion. The doctor said that she cannot abort the child because she was too weak and anemic and suggested to use family planning methods but she replied that she didn't know about family planning methods. Analyzing the scenario, sunrise model by Leininger can be used to evaluate factors for not using contraceptive methods. The prevalent one is the Lack of awareness which limits the use of contraceptives and can be set under the technological component of sunrise model. The same reason was prevalent in above case. 
Moreover, about 222 million women would like to delay or discontinue pregnancy but they don't have any knowledge about contraceptive methods (WHO 2013). Many women believe that using contraceptive will lead to adverse side-effects including weight gain and infertility (Jackson, 2013). Similarly, educational component includes illiteracy that creates a great barrier to contraceptive use and causes lack of women empowerment. Furthermore, due to male dominated society women aren't allowed to take part in household decisions (Pegu et al., 2014). In contrast, reflecting the sociocultural factors women are pressurized by husband and mother in-law to increase their child-bearing and preference for son lowers the use of family planning methods. Likewise, Men believe that increasing family size would increase power and prosperity due to which they disagree with the use of contraceptives (Khan et al., 2011). Many women are restricted to homes due to pardah system and are not allowed to perform their activities outside the home. Similarly, religious believes also hinders contraceptives use. Many believe that children are Godgifted therefore restricting fertility will be against the Islamic rule andmakes God angry (Azmat et al., 2012). Under the political and economic component, family planning services are not accessible due to lack of health facilities in many rural areas. Besides, poor financial condition doesn't allow couple to go for contraceptive measures (Nasir \& Tahir, 2012). Lack of family planning executes great impact on women health and society. According to Nyberg (2008) failure to use contraceptives can cause unintended pregnancies due to which women are highly prone to pregnancy related complications like anemia, Hypertension and obstructed labor. There is also an increased risk of neonatal morbidity and mortality. Besides, unsafe abortion can end-up in hemorrhage, trauma to reproductive organs, and other health-related complication. According to Research and development solutions (2013) 13\% maternal deaths are associated with unsafe abortion. Besides, multiple pregnancies can result in vaginal and uterine prolapsed.

Furthermore, multiple pregnancies can increase financial burden on family and nation resulting in decreased investment on each child and failure to fulfill their basic needs. Additionally, greater number of children will create difficulty for parents to concentrate on each child thus resulting in poor-parenting and low self-esteem of child. Also, women face trouble to participate in social-activities hence affecting her livelihood. Besides, the overly-burdened women can suffer from low self-esteem and other psychological consequences. Moreover, lack of contraceptive use causes difficulty for the government to invest for health and education thus, failing to fulfill millennium developmental goals (Nyberg, 2008). Since lack of family planning is prevalent in Pakistan. Therefore, pertinent steps are essential to be taken. Evaluating the causes and the above scenario, as a nurse we can give awareness to the client and family about the use of family planning and clear misconception about its side-effects. Moreover, using sunrise model, we should communicate therapeutically to build trusting relationship and try to negotiate their cultural practices that promotes women wellbeing. Then respecting their basic values, we should motivate them to modify their behavior to achieve better reproductive health. Subsequently, we should encourage them to maintain their modified behavior which favors women health. Moreover, as a student nurse I can perform my role as an educator and give knowledge to every person I encountered in hospital and community setting by assessing their needs. From community perspective, we can approach high-risk group like adolescent and newly 
married couple and counsel them about importance of family planning. Moreover, Awareness programs can be carried out in collaboration with NGO's to educate religious leader, stakeholders and community leaders about benefits of family planning and its impact on reproductive life. We can taught skills like stitching and needle work to reduce financial burden and easy approach to contraceptive measure.

In conclusion, family planning is essential to promote women right to reproductive health and to fulfill millennium developmental goal of reducing infant mortality and improve maternal health. However, current data shows numerous barriers to the use of family planning. Therefore, important measures should be taken to reduce precipitating factors for the well-being of women and nation.

\section{Acknowledgements}

The authors are pleased to acknowledge Aga Khan School of Nursing and Midwifery.

\section{Conflict of Interest}

We do not have any Conflict of interest.

Source of Funding

Not required

\section{Ethical Clearance}

Not required

\section{References}

- Azmat, S., Mustafa, G., Hameed, W., Ali, M., Ahmed, A. and Bilgrami, M. (2012). Barriers and perceptions regarding different contraceptives and family planning practices amongstmen and women of reproductive age in rural Pakistan: a qualitative study. Pakistan Journal of Public Health, 2(1), pp.1-8.

- Feyistan, B. (2012). Barriers to Family Planning Use in Malawi Opportunities for Social and Behavior Change Communication. 1st ed. United States Agency for International Development, pp.1-39.
- Jackson, A. (2013). Socio-Cultural Barriers to Family Planning Access. 1st ed. SIT Graduate Institute, pp.1-46.

- Khan, A., Hashmi, H. and Naqvi, Z. (2011). Awareness and Practice of Contraception Among Child Bearing Age Women. Journal of Surgery Pakistan, 16(4), pp.179-182.

- Nasir, J. and Tahir, M. (2012). A Literature Based Critical Analysis on the Report Population Stabilization: The Case for Pakistan. Pakistan Journal of social science, 6(2), pp.325-331.

- National Institute of Population Studies Islamabad, Pakistan. (2013). 1st ed. Calverton, Maryland, USA: ICF International, pp.1-392.

- Nyberg, R. (2008). Repositioning Family Planning: Guidelines for advocacy action. 1st ed. Washington: Academy for Educational Development, pp.1-64.

- Pegu, B., Gaur, B., Sharma, N. and Singh, A. (2014). Knowledge, attitude and practices of contraception among married women. International Journal of Reproduction, Contraception, Obstetrics and Gynecology, 3(2), pp.385-388.

- Research and Development Solutions, (2013). Are abortions due to lack of access to family planning services?. U.S. Agency for International Development. pp.1-2.

- Robinson, W. (2012). Family planning in pakistan: an overview. Research and development solutions Policy Briefs Series No. 1. USAID, pp.1-3.

- Sagar, P. (2012). Transcultural Nursing Theory and Models Application in Nursing Education, Practice, and Administration. 1st ed. New york: Springer Publishing Company, pp.5-39.

- WHO | Defining sexual health. (2014). Available at: http://www.who.int/reproductivehealth/to pics/sexual_health/sh_definitions/e 